\title{
Fast five survey results and response
}

\author{
I. Diane Cooper, AHIP \\ DOI: http://dx.doi.org/10.3163/1536-5050.104.2.001
}

A few months ago, we did a "fast five" survey. We wanted to know how readers felt about the October issue of the Journal of the Medical Library Association (JMLA). We limited the survey to 5 questions and got 244 responses.

We thank each respondent for taking the time and effort to help us. Just for background, because it was a "convenience sample," the results are not definitive. A convenience sample is one in which the researchers do not try to get answers from people who represent the population of interest. Typically, convenience samples are obtained by putting a survey notice on an email list such as MEDLIB-L, which we did.

But like many of the articles published in the JMLA, the results, while not definitive, have interest and provoke thought and possible further research. For example, our results suggest that case studies seem popular. So now we will dedicate a special issue to case studies. One or more sections of the JMLA may be less popular. We will see if we can make them more interesting or perhaps drop them as regular features.

A Facebook or Twitter link to the JMLA electronic copy was suggested. We passed this excellent suggestion on to Lauren M. Young, JMLA social media dissemination editor, who is now pursuing it.

Most of our survey respondents serve a mix of clients and could not separate them into dominant groups such as clinicians, students and teachers, or researchers (Table 1 and Figure 1). This supports the egalitarian focus of the JMLA and suggests that researchers should use different classifications than place of work to adjust survey results.

\section{COMMENTS}

Our fast five survey had a place for comments. Thank you to the many respondents who said encouraging things about the JMLA. We take this opportunity to respond to some comments.

\section{Comment: The journal seems different.}

Response: We are making changes. Our responsibility is to accommodate the needs of three health sciences librarianship domains: (1) researchers, (2) readers and users of research, and (3) the science and knowledgebase of health sciences librarianship. These are who we serve. They can be discussed separately, and there is overlap, but they are distinct.

Changes we make are based on our need to serve the three domains. Specific objectives are to produce:

- crisper, more readable articles

- more help for readers to evaluate research results by considering evidence level

- more encouragement for health sciences librarians and informationists to participate in the JMLA

- more articles responsive to the interests and needs of our readers

These changes can make the journal look a little different.

Why are we making these changes? How and when people read in today's world are widely discussed topics. Research indicates that those who read scholarly journals now spend less time browsing and reading yet read more articles [1]. This can be attributed to time pressures and convenient access to more sources. Journals and magazines everywhere are struggling to keep up with their readership. Older media left alone often decline. 
Table 1

Who is the primary user of your library?

If we do not respond to contemporary and anticipated changes in our times, the JMLA could turn into a venerable old MLA vehicle at risk to become dust-covered like the textbooks on our shelves in the basement, aging there, once often read, now frozen in time, fading away. Already, mailed JMLA issues are regularly piled on top of personal "To Read" stacks. As one respondent noted, "I love the journal, but it is always stacked in my to-read box for later and later never comes." So as Margaret M. Bandy, AHIP, FMLA, said in her Doe lecture, to keep relevant to our changing environment, we need to pivot, to advance in different directions [2].

\section{Comment: Has the JMLA changed direction in publication of research?}

Response: We have been using the same research categories and article lengths as before, except we dropped the words "full-length" from the papers category. We reinstituted research communications as a venue for brief observations, but that is not a new category, just a retired one brought back to work. We have continued the policy of Susan Starr, the previous editor, whose rule was that studies "whose results are suggestive rather than definitive are published as research reports" [3]. We endorse Starr's direction as she made other modifications "To encourage an evidence-based approach to health sciences librarianship" [4].

We have not made any changes in direction, but as we all go down the same path, we get better at sorting things out.

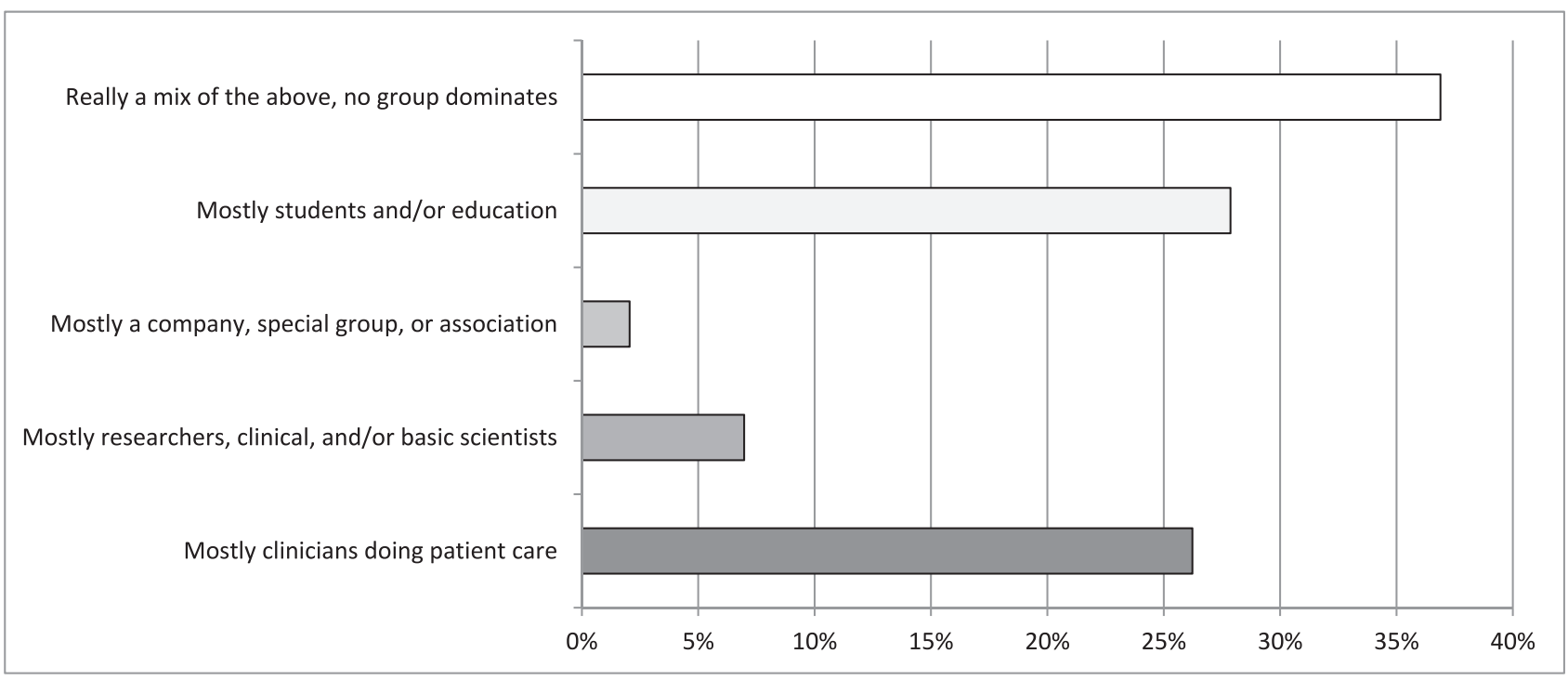

Figure 1

Who is the primary user of your library? 


\section{Comment: What are the criteria for accepting studies?}

Response: There are several channels or sections for publication in the JMLA: letters, commentaries, case reports, and research. In research, there are several classifications, depending on the level of evidence the study presents. Having these classifications helps readers judge how much impact the results should have on their own decision making. We will make these classifications more transparent (see the "JMLA Note" following this editorial [5]).

\section{Comment: It is hard for librarians to do good research.}

Response: Barriers include lack of time, lack of statistical support, and in some cases, lack of institutional support (see the special article by Lessick et al. in this issue [6]). We will invite experts to share useful methods and techniques and will highlight successful approaches in special articles.

\section{Comment: Articles seem shorter.}

Response: There has been some shift to less lengthy articles. This is actually a goal. If you Google "how to write a research paper," you will find overwhelmingly the advice is to delete every unnecessary word and paragraph. One model is to consider the length of an article the "cost" (reader time and effort) and the "benefit" the information that the reader takes away. The goal is to maximize benefit to cost. In this model, shorter print articles that contain the essential information are more likely to be read and can have equal impact [7]. The value of an article depends on the research used, the clarity of presentation, and the acceptance of readers, not the length of the article.

\section{REFERENCES}

1. Tenopir C, King DW, Edwards S, Wu L. Electronic journals and changes in scholarly article seeking and reading patterns. Aslib Proc. 2009;61(1):5-32.

2. Bandy MM. Pivoting: leveraging opportunities in a turbulent health care environment. J Med Libr Assoc. 2015 Jan; 103(1):3-13. DOI: http://dx.doi.org/10.3163/1536-5050.103.1.002.

3. Starr S. JMLA guide to authors. Chicago, IL: Medical Library Association; 2014.

4. Starr S. New submission categories for the Journal of the Medical Library Association [editor's letter]. J Med Libr Assoc. 2014 Jan;102(1):1. DOI: http://dx.doi.org/10.3163/1536-5050.102.1.001.

5. Cooper ID. Research submission categories. J Med Libr Assoc. 2016 Apr;104(2):98-9. DOI: http://dx.doi.org/10.3163/ 1536-5050.104.2.002.

6. Lessick S, Perryman C, Billman, Alpi KM, De Groote SL, Babin TD. Research engagement of health sciences librarians: a survey of research-related activities and attitudes. J Med Libr Assoc. 2016 Apr;104(2):166-73. DOI: http:// dx.doi.org/10.3163/1536-5050.104.2.014.

7. Cooper ID. How to write an original research paper and get it published. J Med Libr Assoc. 2015 Apr;103(2):67-8. DOI: http://dx.doi.org/10.3163/1536-5050.103.2.001.

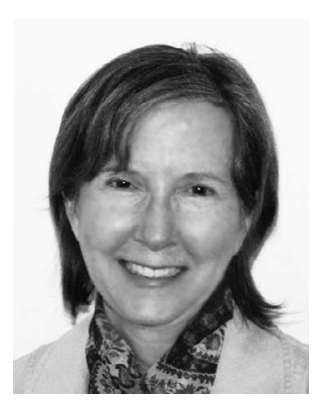

\section{AUTHOR'S AFFILIATION}

I. Diane Cooper, AHIP, jmlaeditorbox@gmail.com, Editor-in-Chief, Journal of the Medical Library Association 